\title{
Investigation of Adolescent Pregnancy Outcomes and Postpartum Depression Frequency and Risk Factors: Prospective Case Control Study
}

\author{
Mehmet Sukru BUDAK ${ }^{1}$, Sedat AKGOL ${ }^{1}$ \\ Diyarbakir, Turkey
}

\section{ABSTRACT}

OBJECTIVE: The aim of this study was to evaluate the frequency of postpartum depression, accompanying risk factors, and obstetrics and neonatal outcomes in adolescent pregnancies.

STUDY DESIGN: This prospective study was conducted on adolescent and adult pregnant patients giving birth in Diyarbakir Gazi Yaşargil Training and Research Hospital of Health Sciences University between January 01 and 31, 2018. Groups were compared in terms of postpartum depression rates and postpartum depression-related factors were also determined in both groups.

RESULTS: The frequency of postpartum depression was higher in adolescent patients than in adult patients but the difference was not considered statistically significant $(p>0.05)$. In adolescent and adult patients, the following factors were found to increase postpartum depression risk: illiteracy, living in an urban area, divorced parents, having fewer than 4 siblings, anemia and caesarean delivery ( $p>0.05$, for all).

CONCLUSION: The study showed no significant difference in postpartum depression rates between adolescent and adult pregnant patients. In both groups, the factors of illiteracy, living in an urban area, divorced parents, anemia, fewer than 4 siblings, and caesarean delivery were found to increase the risk of development of postpartum depression.

Keywords: Adolescent pregnancy, Postpartum depression, Risk factors, Obstetric and neonatal outcomes

Gynecol Obstet Reprod Med 2020;26(2):94-100

\section{Introduction}

Adolescent pregnancy is defined as pregnancy in girls of $\leq 19$ years old (1). Although the worldwide incidence is reported as $11 \%$, this ratio varies between countries, and in Turkey this rate is shown between $8.7 \%$ and $11.5 \%(2-3)$.

\footnotetext{
${ }^{1}$ Department of Obstetrics and Gynecology Health Sciences University Diyarbakır Gazi Yaşargil Education and Research Hospital Diyarbakır, Turkey

Address of Correspondence: $\quad$ Mehmet Sukru Budak

Health Sciences University, Diyarbakır Gazi Yaşargil Training and Research Hospital Department of Obstetrics and Gynecology. 21500 Diyarbakır, Turkey dr.budakms@gmail.com

Submitted for Publication 17.07.2018

Accepted for Publication: 20.12.2018

ORCID IDs of the authors:

MSB:0000-0001-7328-4188.

AS:0000-0001-8609-3049
}

\begin{tabular}{|c|c|}
\hline Quick Response Code: & Access this article online \\
\cline { 2 - 2 } 品 & Website: www.gorm.com.tr \\
& e- mail: info@gorm.com.tr \\
\cline { 2 - 3 } & DOI:10.21613/GORM.2018.818 \\
\hline
\end{tabular}

How to cite this article: Budak MS. and Akgol S. Investigation of Adolescent Pregnancy Outcomes and Postpartum Depression Frequency and Risk Factors: Prospective Case Control Study. Gynecol Obstet Reprod Med 2020;26(2):94-100
The transition to motherhood is an important period of psychological, developmental and biological change in a woman's life (4). Since mothers experience a number of stress sources such as reduced financial resources, role limitations and confusion, social isolation and depressive symptoms, they face stress and this transition period presents greater difficulties, especially for adolescent pregnant patients (5).

Postpartum depression (PPD) is an affective disorder that begins at any time in the first year postpartum (6). There is a significant increase in risk for PPD in adolescent pregnancies, with a frequency of $14-54 \%$; this rate is quite high compared to the rate reported in adult pregnancies (6.8-16.8\%) (7-9). PPD has negative effects on the health of the young mothers themselves and their infants, the mother's work life, the family well-being, and the development of the infant (due to reduced ability to look after the infant) (10). In adolescent pregnancies, in addition to the increased PDD risk, negative outcomes such as low birth weight (LBW), preterm delivery (PD), small for gestational age infant (SGA), perinatal death, pregnancy induced hypertension (PIH), operative vaginal delivery and maternal risk of death, also increase (11). All of these factors make these pregnancies a major public health problem worldwide (12). 
The aim of this study was to examine the frequency of PPD, the accompanying risk factors, and obstetric and neonatal outcomes in adolescent pregnancies.

\section{Material and Method}

The study was designed as a prospective case control study conducted between 1-31 January 2018. Approval for the study was granted by the Ethics Committee of Diyarbakır Gazi Yaşargil Training and Research Hospital of Health Sciences

Figure 1: Edinburgh Postnatal Depression Scale (EPDS)(15)

Name:

Your Date of Birth:

Baby's Date of Birth:
University. All procedures were in accordance with the ethical principles defined by Mandal et al. (13) and with the Helsinki Declaration principles (14). Informed consent was obtained from all participants before starting the study. PPD incidence was determined in all cases using the Edinburgh Postnatal Depression Scale (EPDS) consisting of 10 questions validated for PDD evaluation in adolescents by Friesen et al. (15). The scale was shown to be reliable in its Turkish form by Karacam et al. (16). Patients with a score of $\geq 13$ on the EPDS were evaluated as PPD (16) (Figure 1).

As you are pregnant or have recently had a baby, we would like to know how you are feeling. Please check the answer that comes closest to how you have felt IN THE PAST 7 DAYS, not just how you feel today.

Here is an example, already completed.

I have felt happy:

Yes, all the time

$\mathrm{x}$ Yes, most of the time

No, not very often

This would mean: "I have felt happy most of the time"

No, not at all during the past week.

Please complete the other questions in the same way.

In the past 7 days:

1. I have been able to laugh and see the funny side of things As much as I always could

Not quite so much now

Definitely not so much now

Not at all

2. I have looked forward with enjoyment to things

As much as I ever did

Rather less than I used to

Definitely less than I used to

Hardly at all

*3. I have blamed myself unnecessarily when things went wrong

Yes, most of the time

Yes, some of the time

Not very often

No, never

4. I have been anxious or worried for no good reason

No, not at all

Hardly ever Yes

sometimes Yes,

very often

5. I have felt scared or panicky for no very good reason

Yes, quite a lot

Yes, sometimes

No, not much

No, not at all
*6. Things have been getting on top of me

Yes, most of the time I haven't been ableto cope at all Yes, sometimes I haven't been coping as well as usual No, most of the time I have coped quite well No, I have been coping as well as ever

*7 I have been so unhappy that I have had difficulty sleeping Yes, most of the time

Yes, sometimes

Not very often

No, not at all

*8 I have felt sad or miserable

Yes, most of the time

Yes, quite often

Not very often

No, not at all

*9 I have been so unhappy that I have been crying Yes, most of the time

Yes, quite often

Only occasionally

No, never

10. The thought of harming myself has occurred to me Yes, quite often

Sometimes

Hardly ever

Never 
The study included 100 consecutive adolescent pregnant patients who gave birth to their first child and 100 consecutive adults, aged 20-24 years, who gave birth to their first child. Data in respect of age, educational background (illiterate, primary school, high school, university), place of residence (city, rural), number of siblings, whether the two parents are separated or not were determined using a questionnaire. In all cases, antenatal follow-up, weight gain in pregnancy, hemoglobin, hematocrit, anemia, systolic blood pressure, diastolic blood pressure, preeclampsia, fetal presentation (vertex, nonvertex), cephalopelvic disproportion, fetal distress, preterm birth, term birth, post term birth, birth weight, 1 and 5-minute APGAR score, 5-minute APGAR score <7, SGA (newborns are defined as birth weight and $10^{\text {th }}$ percentile according to the gestational age), large for gestational age (LGA: newborns are defined as birth weight $>90^{\text {th }}$ percentile according to the gestational age) rates were studied. Adolescent and adult mothers were compared in respect of the studied demographic characteristics and obstetrics and neonatal outcomes. In addition, the proportion of adolescents and adults who were diagnosed as PPD as the result of EPDS, the comparison of these rates, and the relationship between the demographic, obstetrics and neonatal outcomes and the PPD were examined. The proportion of adolescent pregnancies of the total number of births in our hospital between January 01, 2017 and December 31, 2017 was also examined. All patients were evaluated using the EPDS at 1 month after the birth.

\section{Statistical Analysis}

All analyses of the study data were performed using MedCalc Statistical Software version 12.7.7 (MedCalc Software bvba, Ostend, Belgium; http://www.medcalc.org; 2013). Descriptive statistics were used to define continuous variables, stated as mean, standard deviation, and minimum, median, maximum values. The Student's $t$ test was used to compare two independent and normal distribution-fit variables. The Mann Whitney U test was used to compare two variables that did not fit with independent and normal distribution. Relationships between categorical variables were evaluated using the Chi-Square test or the Fisher Exact test when appropriate. Logistic regression analysis was performed to examine the effect of the independent variables (with 2 categories) on the categorical dependent variable and the RR values were obtained. A value of $\mathrm{p}<0.05$ was accepted as statistically significant.

\section{Results}

A total of 25043 deliveries were realized in our hospital in 2017 and $9.24 \%(n=2315)$ of these were adolescent pregnancies.

Evaluation was made of a total of 200 pregnant women, comprising 100 adolescents and 100 adults who gave birth in our hospital between 1-31 January, 2018. The mean age (18.5 \pm 0.9 years) and rates of having attended high school (11\%) were significantly lower in the adolescent group compared to the adult group (21.9 \pm 1.2 years; $27 \%)$. The following results were found to be significantly higher $(\mathrm{p}<0.05$, Table I): primary education $(80 \%$ versus $51 \%$ ), systolic blood pressure (106 \pm 10.3 versus $99.7 \pm 12.8)$, diastolic blood pressure $(69.1$ \pm 8.3 versus $64 \pm 8.04)$, 1 -minute APGAR score ( $7.8 \pm 0.4$ versus $7.5 \pm 0.7)$ and 5-minute APGAR score $(9.1 \pm 0.3$ versus 8.9 \pm 0.3 ). No significant difference was observed in the adolescent group compared to the adult group for the following factors: illiteracy ( $9 \%$ versus $18 \%$ ), having divorced parents (11\% versus $7 \%$ ), having non-divorced parents (93\%), PPD (14\% versus $10 \%)$, number of antenatal visits $(8.5 \pm 4.1$ versus $8.4 \pm 2.4)$, weight gain in pregnancy $(11.1 \pm 4.1 \mathrm{~kg}$ versus $11.1 \pm 4.06 \mathrm{~kg})$, hemoglobin $(11.5 \pm 1.6$ versus $11.5 \pm 1.6)$, hematocrit (34.6 \pm 4.4 versus $34.7 \pm 4.5$ ), preeclampsia (4\% versus $3 \%)$, preterm birth $(7 \%$ versus $8 \%)$, post term birth $(4 \%$ versus $3 \%$ ), vertex presentation (79\% versus $90 \%$ ), non-vertex presentation (21\% versus 10\%), CPD (4\% versus $6 \%$ ), fetal distress ( $4 \%$ versus $2 \%$ ), vaginal delivery ( $69 \%$ versus $80 \%$ ), cesarean delivery $(31 \%$ versus $20 \%$ ), birth weight $(3102 \pm$ 486.7 gr versus $3042 \pm 497.4$ gr), SGA ( $6 \%$ versus $4 \%$ ) and LGA ( $6 \%$ versus $2 \%)(p>0.05$, Table I). As the anemia rates (36\% versus $36 \%$ ) were identical in both groups, and there was no case with a 5-minute APGAR score $<7$, no comparison was made for these parameters (Table I). There were no university graduates $(0 \%)$ in the adolescent group, so no comparison was possible with the university graduates of the adult group (4\%) (Table I).

The postpartum depression in adolescent pregnant patients was observed to increase 4.04 times in illiterate patients, 1.75 times in patients living in an urban area, 2.20 times in patients with divorced parents, 1.91 times in patients with $<4$ siblings, 1.12 times in patients with 4-5 siblings, 2.37 times in patients with anemia and 1.23 times in patients giving birth by caesarean delivery, while it developed at a rate of 55\% less in primary education graduates, $38 \%$ in high school graduates, $43 \%$ in rural residents, $55 \%$ in patients with parents who are not divorced, $31 \%$ in patients with $>5$ siblings and $20 \%$ in patients giving birth by vaginal delivery (Table II). The postpartum depression in adult pregnant patients increased 1.13 times in illiterate patients, 2.66 times in university graduates, 1.71 times in patients living in an urban area, 3.32 times in patients with divorced parents, 1.27 times in patients with $<4$ siblings, 1.77 times in patients with anemia and 1.71 times in patients giving birth by caesarean delivery and at a rate of $4 \%$ in primary education graduates, 33\% in high school graduates, $42 \%$ in rural residents, $70 \%$ in patients with parents who are not divorced, $5 \%$ in patients with $4-5$ siblings, $5 \%$ in patients with $>5$ siblings and $42 \%$ in patients giving birth by vaginal delivery (Table II). 
Table I: Distribution of demographic, obstetric, neonatal characteristics and postpartum depression rates of adolescent and adult pregnancies

\begin{tabular}{|c|c|c|c|}
\hline & $\begin{array}{l}\text { Adolescent } \\
n=100\end{array}$ & $\begin{array}{l}\text { Adult } \\
\mathrm{n}=100\end{array}$ & $\begin{array}{c}p \\
\text { value }\end{array}$ \\
\hline Age, (years),[mean $\pm S D]$ & $18.05+0.9$ & $21.9+1.2$ & $<0.001^{1}$ \\
\hline -illiterate & $9(9.0)$ & $18(18.0)$ & $0.097^{3}$ \\
\hline -primary education & $80(80.0)$ & $51(51.0)$ & $<0.001^{3}$ \\
\hline -high school & $11(11.0)$ & $27(27.0)$ & $0.007^{3}$ \\
\hline -university & $0(0.0)$ & $4(4.0)$ & - \\
\hline \multicolumn{4}{|l|}{ Parents, n (\%) } \\
\hline -not divorced & $89(89.0)$ & $93(93.0)$ & $0.458^{3}$ \\
\hline -divorced & $11(11.0)$ & $7(7.0)$ & $0.458^{3}$ \\
\hline Postpartum depression, n (\%) & $14(14.0)$ & $10(10.0)$ & $0.514^{3}$ \\
\hline Number of antenatal visits, (mean \pm SD) & $8.5+4.1$ & $8.4+2.4$ & $0.385^{1}$ \\
\hline Weight gain in pregnancy, $\mathrm{kg}($ mean $\pm S D)$ & $11.1+4.1$ & $11.1+4.06$ & $0.957^{1}$ \\
\hline Anemia, $\mathrm{n}(\%)$ & $36(36.0)$ & $36(36.0)$ & - \\
\hline Hemoglobin, (mean $\pm S D)$ & $11.5+1.6$ & $11.5+1.6$ & $0.976^{2}$ \\
\hline Hematocrit, (mean $\pm S D)$ & $34.6+4.4$ & $34.7+4.5$ & $0.990^{1}$ \\
\hline Preeclampsia, n (\%) & $4(4.0)$ & $3(3.0)$ & $1.00^{3}$ \\
\hline Systolic blood pressure, mmHg, (mean $\pm S D)$ & $106+10.3$ & $99.7+12.8$ & $<0.001^{1}$ \\
\hline Diastolic blood pressure, $\mathrm{mmHg}$, (mean $\pm S D)$ & $69.1+8.3$ & $64+8.04$ & $<0.001^{1}$ \\
\hline Preterm birth, $\mathrm{n}(\%)$ & $7(7.0)$ & $8(8.0)$ & $1.00^{3}$ \\
\hline Term birth, $\mathrm{n}(\%)$ & $89(89.0)$ & $89(89.0)$ & - \\
\hline Post-term birth, n (\%) & $4(4.0)$ & $3(3.0)$ & $1.00^{3}$ \\
\hline \multicolumn{4}{|l|}{ Presentation, $\mathrm{n}(\%)$} \\
\hline -vertex & $79(79.0)$ & $90(90.0)$ & $0.050^{3}$ \\
\hline -non-vertex & $21(21.0)$ & $10(10.0)$ & $0.050^{3}$ \\
\hline Cephalopelvic disproportion, $\mathrm{n}(\%)$ & $4(4.0)$ & $6(6.0)$ & $0.746^{3}$ \\
\hline Fetal distress, $\mathrm{n}(\%)$ & $4(4.0)$ & $2(2.0)$ & $0.678^{3}$ \\
\hline Vaginal delivery, $n(\%)$ & $69(69.0)$ & $80(80.0)$ & $0.105^{3}$ \\
\hline Cesarean delivery, $\mathrm{n}(\%)$ & $31(31.0)$ & $20(20.0)$ & $0.105^{3}$ \\
\hline Birth weight, gram, (mean $\pm S D)$ & $3102+486.7$ & $3042.8+497.4$ & $0.656^{1}$ \\
\hline 1 minute APGAR, (mean $\pm S D)$ & $7.8+0.4$ & $7.5+0.7$ & $0.002^{1}$ \\
\hline 5 minute APGAR, (mean $\pm S D)$ & $9.1+0.3$ & $8.9+0.3$ & $0.003^{1}$ \\
\hline 5 minute APGAR $<7$ & $0(0.0)$ & $0(0.0)$ & - \\
\hline Small for gestational age, $\mathrm{n}(\%)$ & $6(6.0)$ & $4(4.0)$ & $0.745^{3}$ \\
\hline Large for gestational age, $\mathrm{n}(\%)$ & $6(6.0)$ & $2(2.0)$ & $0.279^{3}$ \\
\hline
\end{tabular}

Mann-Whitney $U p^{1}$, Student $t p^{2}$, Fisher's Exact $p^{3}$

Table II: Associations between socio-demographic, obstetric, neonatal factors and postpartum depression among adolescent and adult mothers

\begin{tabular}{|c|c|c|c|c|}
\hline & \multicolumn{2}{|c|}{ Adolescent $(n=100)$} & \multicolumn{2}{|r|}{ Adult $(n=100)$} \\
\hline & Relative risk & (95\% confidence intervals) & Relative risk & (95\% confidence intervals) \\
\hline \multicolumn{5}{|l|}{ Educational status } \\
\hline -illiterate & 4.04 & $1.58-10.30$ & 1.13 & $0.26-4.91$ \\
\hline -primary education & 0.45 & $0.16-1.19$ & 0.96 & $0.29-3.11$ \\
\hline -high school & 0.62 & $0.08-4.30$ & 0.67 & $0.15-2.98$ \\
\hline -university & - & & 2.66 & $0.43-16.25$ \\
\hline \multicolumn{5}{|l|}{ Area } \\
\hline -urban & 1.75 & $0.66-4.60$ & 1.71 & $0.52-5.62$ \\
\hline -rural & 0.57 & $0.21-1.50$ & 0.58 & $0.57-1.91$ \\
\hline \multicolumn{5}{|l|}{ Parents } \\
\hline -non-divorced & 0.45 & $0.14-1.37$ & 0.30 & $0.07-1.15$ \\
\hline -divorced & 2,20 & $0.72-6.71$ & 3.32 & $0.86-12.75$ \\
\hline \multicolumn{5}{|l|}{ Number of siblings } \\
\hline$-<4$ & 1.91 & $0.51-7.11$ & 1.27 & $0.18-8.85$ \\
\hline$-4-5$ & 1.12 & $0.41-3.09$ & 0.95 & $0.26-3.44$ \\
\hline$-\geq 5$ & 0.69 & $0.26-1.83$ & 0.95 & $0.28-3.18$ \\
\hline Anemia & 2.37 & $0.89-6.29$ & 1,77 & $0.55-5.73$ \\
\hline \multicolumn{5}{|l|}{ Type of delivery } \\
\hline -vaginal & 0.80 & $0.29-2.21$ & 0.58 & $0.16-2.05$ \\
\hline -cesarean & 1.23 & $0.45-3.38$ & 1.71 & $0.48-6.04$ \\
\hline
\end{tabular}




\section{Discussion}

Adolescent pregnancies are a global problem and remain as a major contributor to maternal and child mortality and childbirth complications. We primarily investigated the affect of adolescent pregnancy on PPD. Secondarily, obstetric and neonatal outcomes were analyzed. The results of this study showed that the PPD rate (14\%) was higher in adolescent patients compared to adult patients $(10 \%)$ but the difference was not found to be statistically significant. In contrast, Mbawa et al. reported these ratios as $13 \%$ and $7.2 \%$, respectively, and determined a significant difference between the groups (17). Our hospital is located in the southeast of Turkey and serves a large population. Early marriages are widespread and considered normal in this region (18). Thus, the adolescent pregnancy rate for Turkey of $8.7 \%-11.5 \%$ reported by Kaplanoglu et al. (3) was consistent with the rate of $9.24 \%$ in the current study. Due to these conditions in our region, the difference between PPD rates between adolescents and adults may not have been significantly different unlike the study performed by Mbawa et al. (17). In a study by Ozcan et al. (19), PPD incidence was reported as $23.8 \%$ in Turkey. In the current study however, the PPD rates in both groups were lower than those reported by Ozcan et al. (19). The cultural structure of the population living in this region tends to be homogeneous. Living in rural areas, economic transportation factors, and family structure seem to have a greater effect on PPD than the age of marriage. However, as the number of cases in this study was limited, it may be difficult to generalize, and there is a need for further studies with larger series.

In low and middle-income countries, it is estimated that $42 \%$ of pregnant patients have anemia (20). According to the $\mathrm{WHO}$, this ratio is estimated to be $40.2 \%$ for Turkey (21). However, in the current study, the rate of anemia was 36\% in both groups, which was lower than the WHO rate for Turkey, but consistent with the rate of 33.3\% reported by Yilmaz et al. (22) in a previous study in Turkey. Furthermore, in the current study, there was determined to be an increased risk of PPD development in both adolescent and adult patients with anemia. Similar to the results of this study, Y1lmaz et al. (22) and Corwin et al. (23) stated that PPD rates were significantly higher in pregnancies with anemia. Beard et al. (24) reported changes in myelination and neurotransmitter metabolism due to anemia, which were observed to increase PPD risk. The increased risk of developing PPD in pregnancies with anemia in the current study may have been due to the changes in myelination and neurotransmitter metabolism described by Beard et al. (24).

In the current study, it was established that there is an increase of risk of developing PPD in patients with divorced parents in both the adolescent and adult populations. In a study by Kalil et al. (25), negative family relationships were found to increase the PPD rate, while Mbawa et al. (17) stated that the PPD rate increased in patients with divorced parents. These results support the increased risk of developing PPD in patients with divorced parents.

An increased risk of developing PPD was determined in patients giving birth by caesarean delivery in both groups of the current study. Likewise, in an extensive review by Carter et al. (26), there was reported to be a significant increase in the risk of developing PPD with caesarean delivery. Cesarean delivery has been shown to increase maternal complications such as infection rates, risk of bleeding, and risk of blood transfusion, leading to an increase in maternal affective disorder and PPD rate due to anesthesia complications developing simultaneously (27-29). These findings support the increased risk of developing PPD in patients giving birth by caesarean delivery in the current study. In addition, cesarean delivery hampers the mothers returning to their daily lives. In such rural areas women play an important role in daily life (in the house, on the farm) and mothers want to go home quickly even after delivery. Moreover, women are unwilling to give birth by cesarean section for different reasons (30).

In the current study, the rate of primary school education level in the adolescent group was $80 \%$, which was significantly higher than the rate of $51 \%$ in the adult group, while the high school rate was $11 \%$, which was significantly lower than the rate of $27 \%$ in the adult group. There were no university graduates in the adolescent group and this rate was $4 \%$ in the adult group, but no comparison was made between the groups in this regard. The relationship between education level and depression is not fully understood, and there have been no studies investigating the effect of education on PPD (31). However, depressive symptoms may be noticed more easily in people with a higher educational level (32). Similarly, in the current study, the risk of PPD was high in university graduates in the adult group. However, as the risk of developing PPD was higher in those with only primary education in both groups, this result supports the hypothesis of uncertainty about the effect of education level on the development of PPD (31).

In a study by Vigod et al. (33), the risk of developing PPD was found to be greater in urban residents than in those living in rural areas. Consistent with that finding, the risk of developing PPD was determined to be higher in patients living in urban areas in both groups of the current study. In addition, in the current study, the risk of PPD was higher in both groups for patients with fewer than 4 siblings.

The mean systolic and diastolic blood pressure values of the adolescent group in the current study were found to be significantly higher than those of the adult group, whereas there was no significant difference in the pre-eclampsia rates (4\% vs $3 \%$ ). Korencan et al. (34) reported these rates as $4.9 \%$ in the $20-24$ years age group, $4.8 \%$ in the $\leq 19$ years age group and $4.7 \%$ in the $\leq 17$ years age group, which were similar results to those of the current study. 
The results of the current study showed that the mean 1 and 5-minute APGAR scores in the adolescent group were significantly higher than those of the adult group, while there was no case with an APGAR score $<7$ in either group. The rate of cesarean delivery in the adolescent group was $31 \%$, which was not statistically significant, although it was higher than in the adult group. The high mean APGAR scores in the adolescent group may have been due to this high cesarean rate. The non-vertex presentation rate in the adolescent group was $21 \%$ and $10 \%$ in the adult group, with no statistically significant difference determined between the groups. The high non-vertex presentation rate in the adolescent group may also have been due to the higher cesarean delivery rates in this group. As all the pregnancies in this study were the first pregnancies of the patients and in our clinic, all patients with non-vertex presentation in the first pregnancy are delivered by caesarean section provided the cervical canal is not close to fully open. Adolescents may have uterine and cervical maturation deficiencies (35), which could account for the high non-vertex presentation rate $(21 \%)$ in the adolescents of the current study, although it was not found to be statistically significant.

In conclusion, no significant difference was observed in PPD rates between the adolescent and adult pregnancies in this study. In both groups, the factors of illiteracy, living in an urban area, divorced parents, anemia, <4 siblings, and caesarean delivery were found to increase the risk of development of PPD. No difference was found between the groups in terms of obstetric and neonatal outcomes except for the increase in mean systolic-diastolic blood pressure and 1-5 minute APGAR scores in the adolescent group.

The fact that the number of cases was relatively limited can be considered as a limitation of this study. However, the prospective design including the control group constitutes a strength of the research. Furthermore, there is a scarcity of data related to the population studied, which was in southeastern Turkey, where there are specific localized traditions and early marriages are frequent, and therefore, the data are of interest and value. There is a need for prospective studies to examine in detail these PPD-related factors (including adolescent pregnancy) of the population in this region.

Acknowledgments: None.

Conflict of interest: None.

Author contributions: MSB: Writing, concept, design. SA: literature search, data collection or processing, analysis or interpretation

\section{References}

1. Ganchimeg T, Ota E, Morisaki N, Laopaiboon M, Lumbiganon P, Zhang J. et al. WHO Multicountry Survey on Maternal Newborn Health Research Network. Pregnancy and childbirth outcomes among adolescent mothers: a World Health Organization multicountry study.
BJOG. 2014 Mar;121 Suppl 1:40-8. doi: 10.1111/14710528.12630 .

2. World Health Organization. WHO Guidelines on Preventing Early Pregnancy and Poor Reproductive Outcomes: WHO 2011: p.9

3. Kaplanoglu M, Bülbül M, Konca C, Kaplanoglu D, Tabak MS, Ata B. Gynecologic age is an important risk factor for obstetric and perinatal outcomes in adolescent pregnancies. Women Birth 2015 Dec;28(4):e119-23. doi: 10.1016/j.wombi.2015.07.002.

4. Deutsch FM, Ruble DN, Fleming A, Brooks-Gunn J, Stangor C. Information-seeking and maternal self-definition during the transition to motherhood. J Pers Soc Psychol 1988 Sep;55 (3):420-31.

5. Uno D, Florsheim P, Uchino BN. Psychosocial Mechanisms Underlying Quality of Parenting Among Mexican-American and White Adolescent Mothers. J Youth Adolesc 1988;27(5):585-605

6. Reid, V. Meadows-Oliver M. Postpartum depression in adolescent mothers: An integrative review of the literature. J Pediatr Health Care 2007;21(5), 289-298.

7. Kingston D, Heaman M, Fell D, Chalmers B. Comparison of adolescent, young adult and adult women's maternity experiences and practices. Pediatrics 2012 May; 129(5):e1228-37. doi: 10.1542/peds.2011-1447.

8. Hudson DB, Elek SM, Campbell-Grossman C. Depression, self-esteem, loneliness, and social support among adolescent mothers participating in the new parent's role. Adolescence 2000 Autumn; 35(139):445-53.

9. Cantilino A, Barbosa EM, Petribu K. Postpartum depression in adolescents in Brazil: an issue of concern. Arch Womens Ment Health 2007 December;10(6):307-8.

10. Jellinek M, Patel BP, Froehle MC. Bright futures in practice: mental health. Practice Guide, vol. II National Center for Education in Maternal and Child Health .Georgetown University 2002;47-52

11. Black AY, Fleming NA, Rome ES. Pregnancy in adolescents. Adolesc Med State Art Rev 2012;23(1):123-138

12. Sagili H, Pramya N, Prabhu K, Mascarenhas M, Reddi Rani P. Are teenage pregnancies at high risk? A comparison study in a developing country. Arch Gynecol Obstet 2012;285(3):573-7. doi: 10.1007/s00404-011-1987-6.

13. Mandal J, Acharya S, Parija SC . Ethics in human research. Trop. Parasitol. 2011 Jan;1(1):2-3. 14. WMA Declaration of Helsinki,. Ethical Principles for Medical Research Involving Human Subjects.2013. https://www. wma.net/policies-post/wma-declaration-of-helsinki-ethical-principles-fomedical-research-involving-human-subjects/ (Accessed 24 June 2018).

15. Friesen K, Peterson WE, Squires J, Fortier C. Validation of the Edinburgh Postnatal Depression Scale for use with young childbearing women. J Nurs Meas. 2017 Apr 1;25(1):1-16. doi: 10.1891/1061-3749.25.1.E1 
16. Karacam Z, Kitis Y. The Postpartum Depression Screening Scale: Its Reliability and Validity for the Turkish Population. Turkish Journal of Psychiatry. 2008; 19(2):187-196. (Article in Turkish)

17. Mbawa M, Vidmar J, Chingwaru C, Chingwaru W. Understanding postpartum depression in adolescent mothers in Mashonaland Central and Bulawayo Provinces of Zimbabwe. Asian J Psychiatr. 2018 Feb;32:147-150. doi: 10.1016/j.ajp.2017.11.013.

18. Aksit S,Turpculu A. Trends in teenage pregnancy in Turkey. Int J Gynaecol Obstet. 2003;81(1): 55-56.

19. Özcan NK, Boyacıoğlu NE, Dinç H. Postpartum Depression Prevalence and Risk Factors in Turkey: A Systematic Review and Meta-Analysis. Arch Psychiatr Nurs. 2017 Aug;31(4):420-428. doi:10.1016/j.apnu. 2017.04.006.

20. McLean E, Cogswell M, Egli I, Wojdyla D, de Benoist B. Worldwide prevalence of anaemia, WHO Vitamin and Mineral Nutrition Information System, 1993-2005. Public Health Nutr. 2009 Apr; 12(4):444-54. doi:10.1017/ S1368980008002401.

21. Benois B, McLean E, Egli I, Cogswell M. World Health Organization. Worldwide prevalence of anaemia 19932005: WHO global database on anaemia.2008

22, Yılmaz E, Yılmaz Z, Çakmak B, Gültekin İB, Çekmez Y, Mahmutoğlu S. et al. Relationship between anemia and depressive mood in the last trimester of pregnancy. $\mathrm{J}$ Matern Fetal Neonatal Med. 2017 Apr;30(8):977-982. doi: 10.1080/14767058.2016.1194389.

23. Corwin EJ, Murray-Kolb LE, Beard JL. Low hemoglobin level is a risk factor for postpartum depression. J Nutr. 2003 Dec; 133(12):4139-42.

24. Beard JL, Connor JR. Iron status and neural functioning. Annu Rev Nutr. 2003; 23:41-58.

25. Kalil A, Spencer M S, Spieker SJ, Gilchrist LD. Effects of grandmother coresidence and quality of family relationships on depressive symptoms in adolescent mothers. Family Relations.1998;47(4):433-441.
26. Carter FA, Frampton CM, Mulder RT. Cesarean section and postpartum depression: a review of the evidence examining the link. Psychosom Med. 2006 Mar-Apr; 68(2):321-30.

27. Cunningham FG, Leveno KJ, Bloom SL, Hauth JC, Rouse DJ, Spong CY. 23th ed. Chapter 25. New York: McGraw Hill; Williams obstetrics. 2010; pp. 5-37.

28. Rouhi M, Usefi H, Hasan M, Vizheh M. Ethnicity as a risk factor for postpartum depression. Br J Midwifery 2012; 20(6):419-426.

29. Khamsea F. The survey psychosocial factors effect on prevalence of postpartum depression in karaj womens hospital. kousar Medical Journal. 2002; 4(7):327-31.

30. Senturk MB, Cakmak Y, Atac H, Budak MS. Factors associated with successful vaginal birth after cesarean section and outcomes in rural area of Anatolia. Int J Womens Health. 2015 Jul 10; 7:693-7. doi: 10.2147/IJWH.S83800.

31. Di Florio A, Putnam K, Altemus M, Apter G, Bergink V, Bilszta $\mathrm{J}$ et al. The impact of education, country, race and ethnicity on the self-report of postpartum depression using the Edinburgh Postnatal Depression Scale. Psychol Med 2017 Apr;47(5):787-799. doi:10.1017/S00332917160 02087.

32. Cook TM, Wang J. Descriptive epidemiology of stigma against depression in a general population sample in Alberta. BMC Psychiatry 2010 Apr 19;10:29. doi: 10.1186/ 1471-244X-10-29.

33. Vigod SN, Tarosoff LA, Bryja B, Dennis CL, Yudin MH, Ross LE. Relation between place of residence and postpartum depression. CMAJ. 2013 Sep 17;185(13):1129-35. doi: 10.1503/cmaj.122028

34. Korencan S, Pinter B, Grebenc M, Verdenik I.The outcomes of pregnancy and childbirth in adolescents in Slovenia. Zdr Varst. 2017 Oct 9;56(4):268-275. doi: 10.1515/sjph-2017-0036.

35. Da Costa AG, Mauad F, Ferreira AC, Spara P, Mauad FM. Uterine volume in adolescents. Ultrasound Med Biol. 2004 Jan; 30(1):7-10. 